\title{
Analisis Kebutuhan Sistem Informasi Geografis Lahan Pertanian Sayuran dan Buah-buahan di Kota Batu
}

\author{
Supriyono, Faldadinda Farin Maharani
}

\begin{abstract}
Batu City is very famous for its tourism city, but agriculture is still important in improving its performance. In order for growth to be sourced from agriculture can be optimally needed development in agriculture. The aim is to make an analysis of the sistem requirements so that farmers in Batu City can utilize technology so that their work is more optimal. Combined Many types of agricultural plants that we can find in Batu, namely Horticultural crops. Horticultural plants are the most dominant plants in Batu City. Besides Horticultural Plants, Batu City also produces rice plants. Not many areas in Batu City are planted with rice. According to the Agriculture and Forestry Department of Batu City, rice plants are only planted once or twice, which should be done three times. This happens because farmers do not yet understand the suitability of land to grow rice. The results of this study are the results of needs analysis in the form of usecase diagram.
\end{abstract}

Index Terms - analysis, requirements, usecase, vegetables.

Abstrak-- Kota Batu sangat terkenal dengan kota pariwisata, namun pertanian masih berperan penting dalam meningkatkan perekonomiannya. Agar perekonomian yang bersumber dari bidang pertanian dapat optimal diperlukan sebuah pengembangan di bidang pertanian. Tujuan dibuat analisis kebutuhan sistem agar petani di Kota Batu dapat memanfaatkan teknologi sehingga pekerjaan lebih optimal.Tanah di Kota Batu dapat ditanami berbagai jenis tanaman pertanian. Gabungan Banyak jenis tanaman pertanian yang bisa kita temukan di Kota Batu yaitu tanaman Hortikultura. Tanaman Holtikultura merupakan tanaman yang paling dominan di Kota batu. Selain tanaman Hortikultura Kota Batu juga menghasilkan tanaman padi. Tidak banyak daerah di Kota Batu yang ditanami padi. Menurut Departemen pertanian dan Kehutanan Kota Batu, Tanah tanaman padi hanya ditanami padi sekali atau dua kali yang harusnya dilakukan 3 kali setahun. Hal itu terjadi karena petani belum mengetahui kecocokan lahan untuk menanam padi. Hasil dari penelitian ini adalah output analisis kebutuhan berupa usecase diagram.

Kata Kunci - analisa, kebutuhan, usecase, sayuran.

Supriyono, Teknik Informatika, Universitas Islam Negeri(UIN) Maulana Malik Ibrahim Malang, Indonesia (email priyono@ti.uinmalang.ac..id)

Faldadinda Farin Maharani, Teknik Informatika, Universitas Islam Negeri(UIN) Maulana Malik Ibrahim Malang, Indonesia

\section{Pendahuluan}

DEngGunAAN teknologi informasi pada saat ini sudah tidak bisa dihindari. Salah satunya penggunaan teknologi untuk informasi untuk lahan pertanian pada lahan pertanian didaerah perkotaan Batu. Daerah perkotaan Batu lebih dikenal sebagai kota pariwisata. Namun, sektor pertanian masih memainkan peran penting dalam perekonomian Kota Batu [1]. Penelitian terkait menyebutkan kota Batu pada tahun 2013, dicatat oleh BPS bahwa luas area penanaman sawah di Kota Batu adalah 8.275.637 $\mathrm{m}^{2}$, di Kecamatan Batu adalah 1.226.352 $\mathrm{m}^{2}$, di Kecamatan Junrejo adalah $5.922 .992 \mathrm{~m}^{2}$, dan di Kecamatan Bumiaji adalah $1.126 .293 \mathrm{~m}^{2}$ [2]. Menurut hasil wawancara dari Departemen Pertanian dan Kehutanan Kota Batu, dalam waktu satu tahun, tanah tanaman padi hanya ditanami padi sekali atau dua kali yang harus dilakukan 3 kali setahun. Itu karena petani tidak tahu tanah itu sebenarnya cocok atau tidak untuk tanaman padi. Dinas Pertanian dan Kehutanan Kota Batu saat ini belum memiliki data yang terkait dengan lahan yang sebenarnya sesuai atau tidak untuk ditanami padi. Data diperlukan, sehingga dapat digunakan sebagai referensi dalam mengelola lahan pertanian. Pemanfaatan teknologi pada lahan pertanian sayuran dan buahbuahan dapat menggunakan sistem informasi geografis. Dengan adanya sistem informasi geografis mengenai kecocokan lahan pertanian, petani tidak perlu bingung saat menentukan jenis tanah. Kecocokan jenis tanah dapat terdeteksi dengan sistem ini.

Pembuatan sistem informasi yang tepat sangat berpengaruh pada hasil kecocokan lahan pertanian sayuran dan buah-buahan. Sebelum membuat sistem informasi geografis memerlukan analisis kebutuhan sistem perangkat lunak. Kebutuhan suatu perangkat lunak sistem harus bertemu, fungsi yang harus dipenuhi untuk mencapai tujuan tersebut, dan kemungkinan kendala yang mempengaruhi sistem. Manajemen kebutuhan merupakan pendekatan untuk memperoleh, melakukan dokumentasi, melakukan proses pengaturan, dan mengidentifikasi perubahan suatu requirement. Serangkaian proses kegiatan dan semua hal dokumentasi yang dibutuhkan untuk dapat membuat suatu manajemen requirement yang lengkap dan cukup memadai. Tools yang dapat digunakan dan sangat 
akurat untuk kegiatan manajemen kebutuhan sistem adalah menggunakan diagram usecase. Kualitas produk dari perangkat lunak memiliki dampak yang cukup penting dalam mengukur standard perangkat lunak yang dikembangkan [3].

Penelitian terkait pendekatan usecase diagram menggunakan fungsi tertentu dari sistem secara tekstual, sebagai skenario tindakan dan tanggapan ditulis dalam bahasa yang natural [4]. Penggunaan bahasa natural menjadikan kasus penggunaan teks sebagai pendekatan yang ideal untuk berkonsultasi dengan perilaku yang dimaksudkan dari sistem yang dikembangkan, yaitu Sistem Under Discussion (SuD) dengan pengguna atau bagian pemangku kepentingan. Dalam pemodelan Usecase, masing-masing sistem ditentukan oleh satu set Use-case menggambarkan transaksi sistem, atau fungsi. Aktor dalam konteks ini adalah agen (manusia atau sebaliknya) yang memicu fungsi sistem. Pendekatan Use-case telah termasuk dalam Unieed Modelling Language (UML), yang menggabungkan sejumlah teknik analisi populer berorientasi objek

\section{MOdEL SiSTEM}

Desain sistem menentukan bagaimana sistem akan mencapai apa yang seharusnya dicapai dan mengkonfigurasi komponen perangkat lunak dan perangkat keras dari suatu sistem sehingga ke sistem akan benar-benar memuaskan rancang bangun yang telah di tetapkan pada akhir tahap analisis sistem [5]. Desain sistem merupakan hal yang penting dalam suatu sistem untuk mengetahui alur sistem tersebut. Desain sistem pada sistem rekomendasi kelayakan lahan pertanian sayuran dan buah-buahan terdapat pada gambar 1.

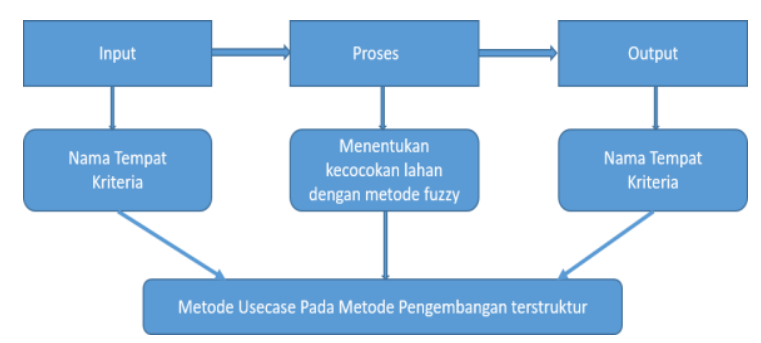

Gambar 1. Desain Sistem Rekomendasi Lahan

Skenario adalah dasar untuk deskripsi dan pemahaman sistem jenis apa pun. Hal itu dapat memberikan basis bersama ketika mencoba untuk menggabungkan pendekatan pemodelan yang berbeda. Penelitian terkait mempertimbangkan peran khusus mereka dalam menghubungkan identifikasi kebutuhan sistem dan pemodelan Use-case [6]. Penelitian tersebut melakukan pemodelan dalam konteks menguji potensi keuntungan dari penggunaan teknik-teknik desain sistem dalam melakukan kombinasi metode. Identifikasi kebutuhan sistem mendukung perencanaan strategis untuk desain atau peningkatan bisnis. Hal itu melibatkan pengembangan model sistem untuk mengidentifikasi kegiatan yang harus dilakukan organisasi untuk memenuhi tujuannya. Pemodelan use-case adalah teknik rekayasa kebutuhan sistem yang juga mengarah pada identifikasi kegiatan sistem, tetapi lebih banyak didorong oleh kebutuhan pengguna sistem daripada kebutuhan sistem itu sendiri. Perspektif yang berbeda namun saling melengkapi ini menunjukkan bahwa teknik mana pun dapat digunakan untuk membantu memvalidasi model yang lain. Requirement Engineering muncul sebagai cara untuk meningkatkan pengembangan Use-case dan Unified Modelling Language secara umum.

Untuk memenuhi kebutuhan pelanggan, kegiatan Rekayasa Kebutuhan memainkan peran kunci dalam pengembangan perangkat lunak. Pendekatan umum untuk mengidentifikasi, membuat model, dan menganalisis persyaratan pengguna untuk jenis sistem perangkat lunak tertentu mungkin tidak sepenuhnya efektif. Penelitian terkait membahas spesifikasi perangkat lunak dalam membangun suatu sistem informasi manajemen [7]. Sistem ini dapat digunakan untuk menyelesaikan masalah yang sulit atau tidak mungkin diselesaikan oleh individu atau sistem secara parsial. Dalam perancangan sistem yang diusulkan dengan pendekatan usecase diagram.

Metode yang diperlukan untuk menganalisis kebutuhan adalah metode usecase. Dalam perancangan sistem penggunaan usecase sangat penting sekali dalam melakukan analisa kebutuhan dari sistem yang akan dikembangkan. Penekanan pada pembahasan hanya difokuskan untuk menyusun keperluan pengguna yang kemudian diolah menjadi fitur dari aplikasi. Fitur-fitur inilah yang kemudian dibuatkan use case-nya. Tahap selanjutnya adalah melakukan pemodelan proses menggunakan pendekatan usecase diagram. Usecase bertujuan untuk menganalisa sistem mulai dari sistem itu digunakan sampai dengan interaksi sistem yang lainnya. Hal yang paling penting dalam pengembangan sistem adalah melakukan identifikasi kebutuhan fungsional sistem yang dikembangkan.

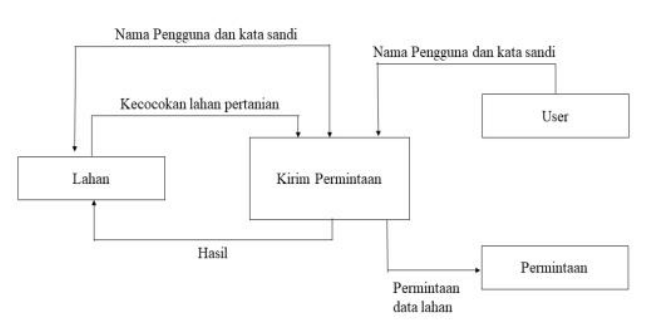

Gambar 2. Diagram Alir Permintaan

Pada gambar 2 terlihat diagram aliran data logis dari proses pengiriman permintaan. Diagram alir permintaan tersebut menunjukkan bahwasanya setiap pengguna menunjukkan setiap pengguna sistem menginputkan kata sandi kedalam sistem. Pengguna sistem menginputkan nama pengguna dan kata sandi yang sudah terdaftar dalam database kemudian sistem akan melakukan verifikasi dan validasi hak akses. Setelah nama pengguna dan kata sandi sudah berhasil 
diverifikasi secara otomatis oleh sistem maka akan muncul menu sesuai dengan hak akses pengguna.

\section{Pembuatan Prototype}

Prototype adalah langkah penting menuju implementasi akhir dari segala jenis kebutuhan sistem [8]. Maka dari itu sebelum membuat perangkat lunak dibutuhkan prototype yang sesuai dengan perangkat lunak. Berikut metupakan prototype dari sistem rekomendasi lahan pertanian sayuran dan buah-buahan. Gambar 3 menunjukkan prototype dari sistem rekomendasi lahan pertanian. Halaman pertama dimulai dengan menu login. Admin dapat memasukkan nama dan password. Setelah berhasil login user akan berpindah ke halaman selanjutnya yaitu halaman home. Pada halaman ini user dapat memilih menu lahan dan kriteria lahan sayuran. User juga dapat melakukan aksi tambah, edit dan hapus data.

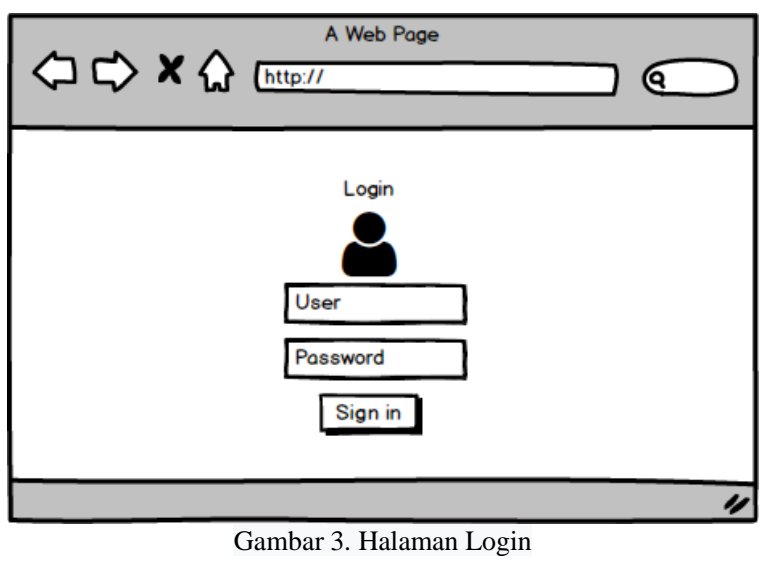

Setelah berhasil login maka pengguna sistem dapat berpindah ke halaman selanjutnya yaitu halaman home. Pada halaman ini pengguna dapat memilih menu lahan dan kriteria lahan sayuran. pengguna juga dapat melakukan aksi tambah, edit dan hapus data. Gambar 4 merupakan halaman ketika pengguna sistem memilih menu ketika proses login berhasil.

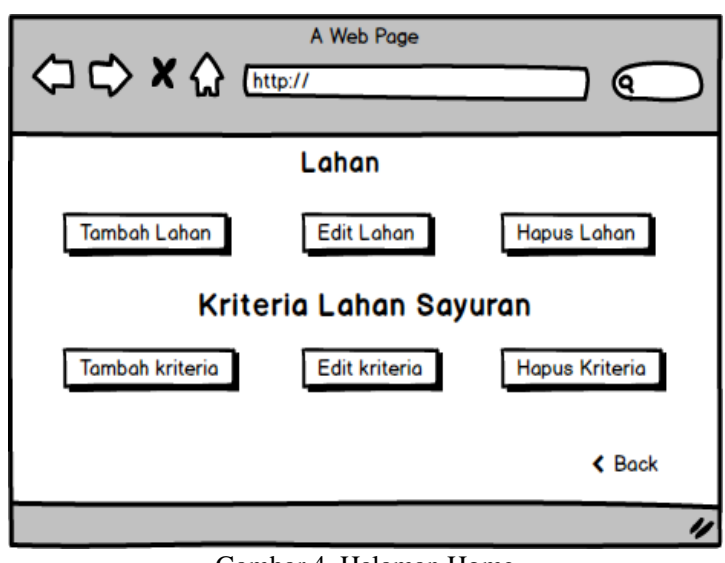

Gambar 4. Halaman Home

Gambar 5 merupakan halaman ketika pengguna memilih menu lahan. Terdapat daftar nama tempat dari lahan yang akan diuji kelayakannya. Selain terdapat daftar nama tempat dan kecamatan, pengguna sistem juga dapat menambahkan data. Cara menambahkan data dengan cara memilik pilihan menu tambah lahan.

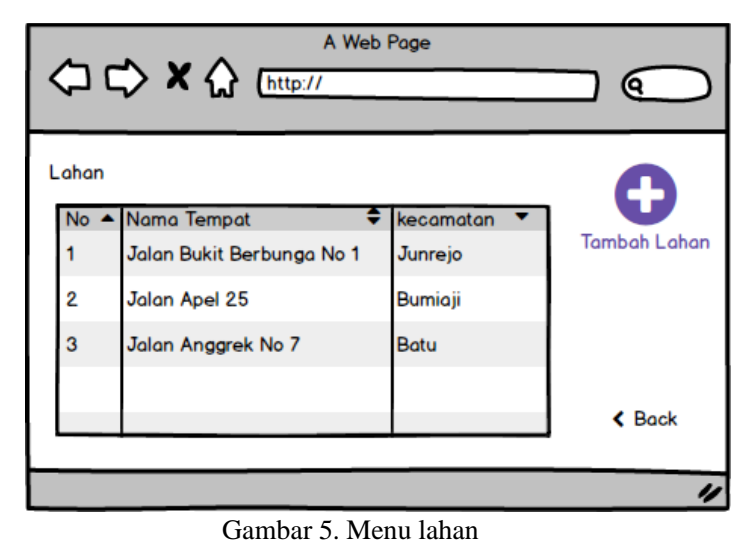

Setelah user mengklik tambah lahan maka akan muncul tempat untuk mengisi nama tempat dan kecamatan. Kemudian data dapat berhasil di simpan. Proses tersebut dalam ranangan kebutuhan fungsional sistem yang dikembangkan ditunjukkan pada gambar 6 .

Selain tambah lahan user juga dapat menambahkan kriteria. Pada halaman kriteria menampilkan daftar

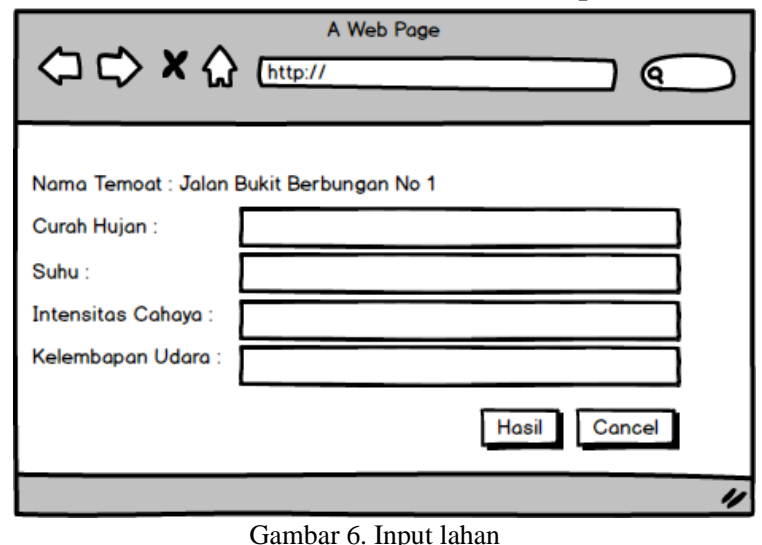

kriteria lahan bersama nama tempatnya. Proses terebut dapat ditunjukkan pada gambar 7 .

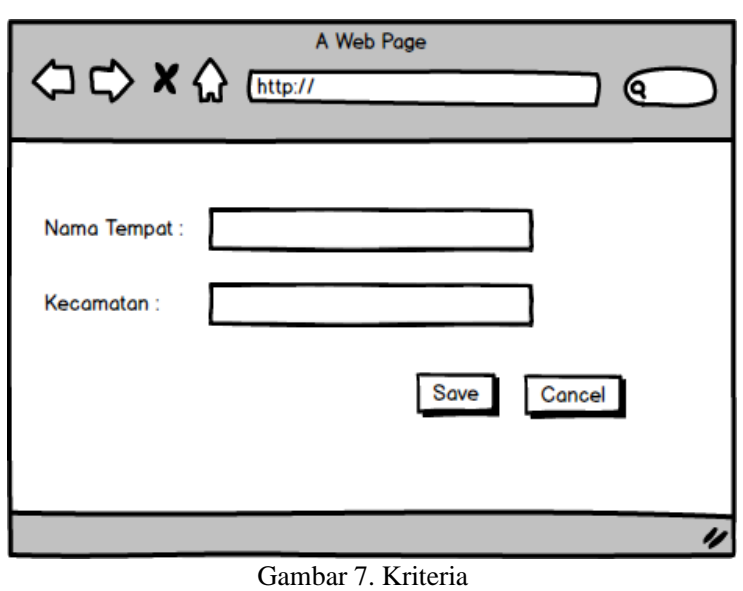


Gambar 8 menunjukkan gambar tambah kriteria. Pengguna dapat menambahkan data curah hujan, suhu,

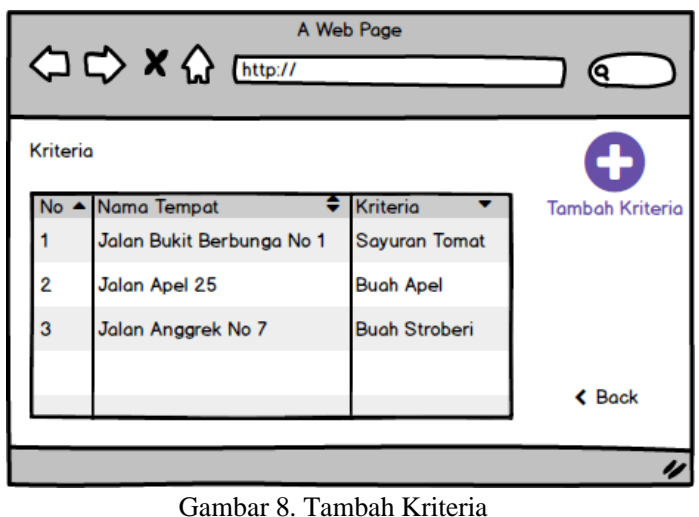

intensitas cahaya dan kelembapan udara. Jika sudah menambahkan semua data maka akan diketahui hasil kecocokan lahannya.

Setelah menambahkan data hasil akan terlihat pada halaman hasil yang ditunjukkan seperti pada gambar 9 .

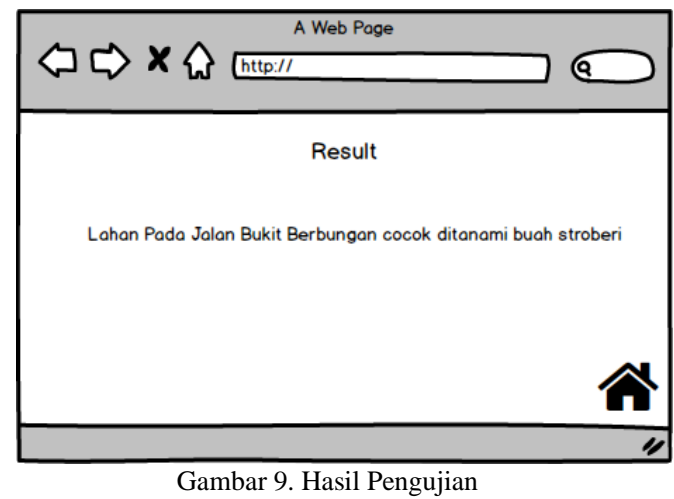

Hasil kecocokan lahan akan dihitung lalu ditampilkan datanya. Pada halaman hasil dapat diketahui kecocokan lahan pertanian sayuran atau buah-buahan.

\section{HASIL DAN PEMBAHASAN}

Kebutuhan sistem yang dikembangkan

1. Memerlukan suatu sistem rekomendasi yang baru dan mudah untuk mengetahui jenis lahan yang cocok untuk ditanami sayuran dan buah-buahan.

2. Memerlukan basis data yang mampu memuat data secara lengkap data-data kriteria yang cocok untuk dapat ditanami sayuran atau buah-buahan.

3. Lain-lain.

\section{Fitur Sistem}

1. Sistem memiliki fungsi yang dapat digunakan pengguna untuk menentukan kecocokan lahan pertanian sayuran dan buah-buahan.

2. Sistem memiliki fungsi untuk memuat secara lengkap data-data kriteria yang cocok ditanami sayuran atau buah-buahan.

3. Lain-lain.

Tabel 1 merupakan hubungan antara keperluan dan fitur beserta hubungan antara fitur dan use case.
Tabel 1. Hubungan keperluan dan fitur

\begin{tabular}{|l|l|l|}
\hline \multicolumn{1}{|c|}{ Keperluan } & \multirow{2}{*}{1} & 2 \\
\cline { 1 - 1 } \multicolumn{1}{|c|}{ fitur } & & \\
\hline 1 & $\mathrm{~V}$ & \\
\hline 2 & & $\mathrm{~V}$ \\
\hline 3 & $\mathrm{~V}$ & \\
\hline
\end{tabular}

Hubungan yang dapat digambarkan tidak selalu bersifat pemetaan satu-satu. Bisa saja satu keperluan dipetakan dalam dua fitur dan sebagainya. Hubungan kebutuhan dan fitur digambarkan pada tabel berikut.

Use case ini menggambarkan proses permintaan admin tentang kecocokan lahan pertanian sayuran dan buah-buahan. Admin dapat menginpput beberapa kriteria yang dibutuhkan untuk mencapai kecocokan lahan. Aktornya adalah admin sistem. Tabel 2

Tabel 2. Analisa Kebutuhan Sistem Pendekatan Usecase

\begin{tabular}{|c|c|}
\hline Nama use case & Sistem rekomendasi lahan pertanian \\
\hline Pembuat & Supriyono / Faldadinda Farin \\
\hline Tanggal & $8 / 11 / 2019$ \\
\hline $\begin{array}{l}\text { Deskripsi } \\
\text { singkat }\end{array}$ & $\begin{array}{l}\text { Use case ini menggambarkan proses } \\
\text { jalannya sistem rekomendasi } \\
\text { kelayakan lahan pertanian sayuran } \\
\text { dan buah-buahan di Kota Batu. } \\
\text { Dimana admin dapat input, edit dan } \\
\text { hapus data. Setelah data terkumpul } \\
\text { maka dapat dihitung kelayakan } \\
\text { lahannya. }\end{array}$ \\
\hline Aktor utama & Pengguna sistem \\
\hline \multicolumn{2}{|l|}{ Aliran Kejadian } \\
\hline Aktor & Sistem \\
\hline $\begin{array}{l}\text { 1. Use case } \\
\text { mulai ketika } \\
\text { user meminta } \\
\text { permintaan }\end{array}$ & $\begin{array}{l}\text { 2. Sistem meminta Nama Pengguna } \\
\text { dan Kata Sandi. }\end{array}$ \\
\hline \multirow[t]{2}{*}{$\begin{array}{l}\text { 3. User } \\
\text { memasukkan } \\
\text { Nama } \\
\text { Pengguna dan } \\
\text { Kata Sandi } \\
\end{array}$} & $\begin{array}{l}\text { 4. Sistem memvalidasi Nama } \\
\text { Pengguna dan Kata Sandi. }\end{array}$ \\
\hline & $\begin{array}{l}\text { 5. Sistem membuka layar Permintaan } \\
\text { yang berisi: Lahan dan kriteria }\end{array}$ \\
\hline $\begin{array}{l}\text { 6. User } \\
\text { memilih lahan }\end{array}$ & $\begin{array}{l}\text { 7. Sistem membuka layar lahan yang } \\
\text { berisi : Nama dan kecamatan }\end{array}$ \\
\hline $\begin{array}{l}\text { 8. User } \\
\text { menyimpan } \\
\text { data }\end{array}$ & $\begin{array}{l}\text { 9. Sistem memasukkan permintaan ke } \\
\text { dalam basis data dan merespon } \\
\text { dengan menampilkan pesan bahwa } \\
\text { data tersimpan lalu data ditampilkan } \\
\text { dalam list }\end{array}$ \\
\hline
\end{tabular}

menunjukkan rancangan usecase diagram pada sistem rekomendasi lahan pertanian dikota Batu Propinsi Jawa Timur.

Gambar 10 merupakan diagram usecase dari rancangan sistem yang dikembangkan. Aktor yang terlibat dari pengembangan sistem yang diusulkan melibatkan admin, pengguna sistem dan operator. Pada perancangan Sistem Informasi Geografis lahan pertanian tersebut menunjukkan beberapa proses yang dilakukan diantaranya adalah cek pengguna system, memilih menu, proses input data dan generate laporan. Hal itu menunjukkan tingka kompleksitas system yang 
dikembangkan. Oleh sebab itu diperlukan analisa kebutuhan system yang detail agar system dapat berjalan dengan maksimal dan sesuai dengan kebutuhan pengguna.

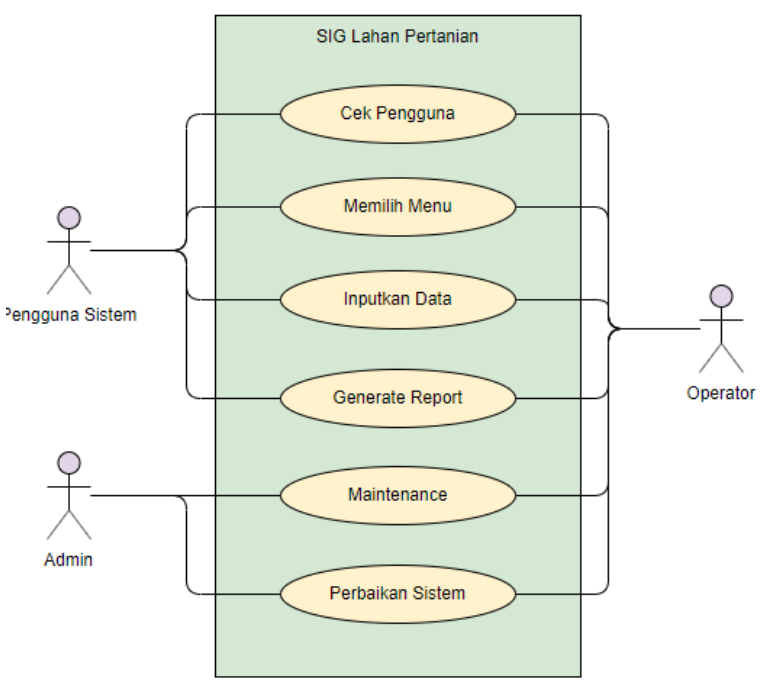

Gambar 10. Usecase Diagram

\section{KESIMPULAN}

Analisis kebutuhan menggunakan pendekatan metode software delopment life cycle (SDLC) dengan mengidentifikasi kebutuhan sistem dengan usecase diagram dapat dengan mudah diterapkan pada perancangan sistem dengan menggunakan metode terstruktur. Hal ini dapat terjadi karena diagram usecase umumnya digunakan dalam pengembangan berorientasi objek namun pada dasarnya diagram usecase tidak memiliki sifat-sifat objek yang dimaksud. Diagram usecase lebih sebagai urutan aksi dari aktor dan respon dari sistem. Maka dari itu penerapannya pada metode pengembangan terstruktur tidak ditemukan unsur permasalahan sama sekali. Bahkan dengan penggunaan diagram usecase, penggambaran diagram aliran data menjadi mudah dilakukan, sehingga dapat dengan tepat menganalisis dan menentukan kebutuhan sistem.

\section{REFERENSI}

[1] N. Lusiana, B. Rahadi, and F. Anugroho, "Identification of Suitability Agriculture Landuse and Water Contamination Level as Agricultural Intensification Effect in Upstream of Brantas Watershed, Batu," J. Teknol. Pertan., vol. 18, no. 2, pp. 129-142, 2017.

[2] A. K. Nisyak, F. Ramdani, and Suprapto, "Web-GIS development and analysis of land suitability for rice plant using GIS-MCDA method in Batu city," 2017 Int. Symp. Geoinformatics, ISyG 2017, vol. 2018-January, pp. 24-33, 2018.

[3] S.Supriyono, N. Kadir, J. Febriana, and E. P. Rahayu, "Kualitas Perangkat Lunak pada E-book," vol. 11, no. 1, pp. 9-13, 2019.

[4] I. Essebaa and S. Chantit, "Tool support to automate transformations from SBVR to UML use case diagram," ENASE 2018 - Proc. 13th Int. Conf. Eval. Nov. Approaches to Softw. Eng., vol. 2018-March, no. Lim, pp. 525-532, 2018.

[5] A. M. Yuwantoko, S. Daniel, and A. S. Ahmadiyah, "Pembuatan Kakas Bantu untuk Mendeteksi Ketidaksesuaian Diagram Urutan (Sequence Diagram) dengan Diagram Kasus Penggunaan (Use Case Diagram)," J. Tek. ITS, vol. 6, no. 1, pp. 71-75, 2017.

[6] S. Vemuri, S. Chala, and M. Fathi, "Automated use case diagram generation from textual user requirement documents," Can. Conf. Electr. Comput. Eng., 2017.

[7] M. Susilowati and A. A. Kusuma, "Software Requierement Specification Sistem Informasi Manajemen," SMARTICS J., vol. 5, no. 1, pp. 27-33, 2019.

[8] A. Castro, P. Zuniga, F. A. Uribe, and E. Barocio, "Synchronous generator emulator prototype as a testbed for electric equipment," IEEE Trans. Energy Convers., vol. 30, no. 1, pp. 404-406, 2015. 